La négativité de la sérologie HIV permet aux couples de construire leur projet d'enfant "comme si la vie amoureuse commençait avec leur relation actuelle".

Dans tous les cas de notre expérience, l'attente $\mathrm{du}$ résultat d'une sérologie HIV est anxiogène mais, si le médecin s'y prête par une attitude d'écoute, permet aux patients de verbaliser leurs craintes, leurs réticences, leur culpabilité. Ne pas dire qu'on effectue ce dépistage chez un patient prive en outre ce dernier de l'opportunité de s'informer sur le SIDA et sur la sexualité. L'annonce d'une sérologie positive est toujours traumatisante mais elle l'est moins si le médecin s'est livré à une préparation psychologique lors de la proposition du dépistage. Cette information initiale est une étape fondamentale même si elle ne résout pas tout. Elle permet d'une part de distinguer sérologie positive, c'est-à dire portage biologique du virus et SIDA maladie mortelle plaçant l'individu au ban de la société, d'autre part d'aider les patients à verbaliser leurs sentiments de culpabilité : culpabilité d'avoir eu des expériences sexuelles ou toxicomaniaques tabous, culpabilité d'avoir eu des partenaires multiples, peur d'être sanctionné par le portage du virus du SIDA et/ou l'infertilité. Ne pas parler de ce dépistage et le pratiquer à l'insu des malades "pour ne pas les inquiéter inutilement" paraît un prétexte peu valide qui masque mal la peur des médecins face au SIDA et à la mort. Aborder la situation avec franchise et compétence est la condition d'un véritable dialogue constructif avec nos patients.

\section{REFERENCES}

1 - Casadonte P.P., Don Des Darlais, Smith R., Novart A., Hemdal P. Psychological and behavioral impact of learning HTLV III/LAV antibody test results. Conférence internationale sur le SIDA, Paris, 23-25 juin 1986

2 - Clement J.L. La situation psychosexuelle des infectés par HIV. Médecine et Hygiène, 1988 : $1064-1066$

3 - Rozenbaum W. SIDA : guide pratique 1990: information et conseils. Impact médical, 1990, $62: 36-38$
4 - Schmitt L. , Lefranc G., Lemaire A., Fabre A.P, Moron P. De l'agressivité au suicide chez les porteurs du VIH. Annales Médico-psychologiques, 1988, 3; 237-239

5 - Seidl 0 . Life in anxiety, psychosomatic reactions following the knowledge of positive results of HTLV III/LAV antibody test. Conférence internationale sur le SIDA, Paris, 23-25 juin 1986

RESUME : Une sérologie HIV a été proposée à 127 patients consultant pour infertilité. Trois sérologies ont été positives. La prescription de cet examen a été expliquée et justifiée aux patients au cours d'un entretien particulier. A cette occasion, les consultants ont évoqué leur sexualité, leurs inquiétudes face au SIDA, leur culpabilité lors de situations les ayant exposés au risque de contamination par le virus. Les patients séropositifs ont dû à la fois faire le deuil de leur santé et de leur fertilité. Mots clés: infertilité masculine, sexualité, syndrome d'immunodéficience acquise.

Andrologie, 1991, $1: 38-39$

\title{
CONGRÈS ANNUEL DE LA SALF
}

\begin{tabular}{ll} 
RÉUNION COMMUNE & GEMEINSCHAFTSKONGRESS \\
\hline SOCIETE D'ANDROLOGIE DE LANGUE FRANÇAISE & DEUTSCHE GESELLCHAFT FüR ANDROLOGIE
\end{tabular}

\section{Strasbourg, Palais des Congrès 29 et 30 novembre 1991}

- L'andrologue et la puberté

M. G. ForestT (Lyon) - 0. P. Steeno (Leuven)

- Le tissu érectile

P. Bondil (Salon de provence) - C. Stief (Hanover) - E. Wespes (Bruxelles)

- La prostate et la fertilité

G. Arvis (Paris) - G. Aumuller (Marburg)

- Nouvelles thérapeutiques en Andrologie

W. B. Schill (Giessen) - M. Schouman (Paris)

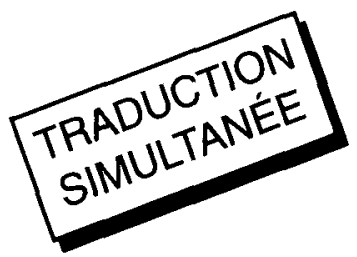

Secrétariat: Dr André CLAVERT CECOS ALSACE - HOSPICES CIVILS DE STRASBOURG

1 Place de l'Hôpital - 67091 STRASBOURG CEDEX

TEL. 88365270 - FAX. 88356130 